\title{
Gevisto
Observatório
}

\section{EM CARTAZ: festivais de cinema de arquivo - preservação e público}

EM CARTAZ: archive film festivals preservation and public

EM CARTAZ: festivales de cine de archivo - preservación y publico

\section{Juliana Muylaert Mager ${ }^{1}$ Ana Maria Mauad ${ }^{2,3}$}

\section{RESUMO}

Nas últimas décadas, observa-se o surgimento de festivais dedicados ao cinema de arquivo. No Brasil, foi criado em 2002, pelo Arquivo Nacional, o Recine Festival Internacional de Cinema de Arquivo, evento que foi substituído pelo Arquivo em Cartaz em 2015. O fenômeno dos festivais se relaciona com o tratamento do patrimônio audiovisual ao longo do século XX e XXI, sendo inseparável da trajetória das instituições arquivísticas. Neste artigo, pretende-se, por meio da análise dos dois festivais, discutir como esses eventos trabalham a tensão entre exibir e preservar, duas das principais funções das cinematecas, colocando em diálogo questões sobre patrimônio/preservação e a relação entre os arquivos e seus públicos.

PALAVRAS-CHAVE: Arquivo; Patrimônio Audiovisual; Público(s); Festivais de cinema.

\footnotetext{
${ }^{1}$ Doutoranda em História e mestre pela Universidade Federal Fluminense (UFF), graduada em História pela Universidade Federal de Uberlândia. E-mail: jumuylaert@gmail.com.

2 Doutora em História Social pela Universidade Federal Fluminense, com pós-doutorado no Museu Paulista da USP. Graduada em História pela Universidade Federal Fluminense (UFF). Atualmente é professora titular do Departamento de História e Coordenadora do Programa de Pós-Graduação em História. E-mail: anamauad@id.uff.br.

3 Endereço de contato das autoras (por correio): Universidade Federal Fluminense (UFF). Programa de Pós-Graduação em História. R. Miguel de Frias, 9, Icaraí, Niterói, RJ, Brasil.
} 


\title{
Gevisto
Observatório
}

ISSN n² 2447-4266

Vol. 3, n. 2, Abril-Junho. 2017

DOI: http://dx.doi.org/10.20873/uft.2447-4266.2017v3n2p283

\begin{abstract}
In the last decades, we observe an increase in the number of festivals dedicated to archival films. The Brazilian National Archive, for instance, hosted Recine Festival Internacional de Cinema de Arquivo from 2002 to 2014, and, since 2015, its sucessor festival called Arquivo em Cartaz. This "festival phenomenon" can be related to how audiovisual heritage has been viewed in the 20th and 21st centuries, being, thus, closely linked to the developement of film archives. This article aims at analysing the aforementioned festivals, in order to discuss how these events coped with the tension between exhibiting and preserving - the two foremost goals of a cinematheque -, establishing dialogues over issues such as heritage/preservation and the relationship between archives and its viewing public.
\end{abstract}

KEYWORDS: Archive; Audiovisual Heritage; Public; Film festivals

\section{RESUMEN}

En las últimas décadas, se observa el surgimiento de festivales dedicados al cine de archivo. En Brasil, fue creado en 2002 por el Archivo Nacional, Recine Festival Internacional de Cinema de Arquivo, evento que fue sustituido por el Arquivo em Cartaz en 2015. El fenómeno de los festivales se relaciona con el tratamiento del patrimonio audiovisual a lo largo del siglo $\mathrm{XX}$ y $\mathrm{XXI}$, siendo inseparable de la trayectoria de las instituciones archivísticas. En este artículo, se pretende, por medio del análisis de los dos festivales, discutir cómo esos eventos trabajan la tensión entre exhibir y preservar, dos de las principales funciones de las cinetecas, colocando en diálogo cuestiones sobre patrimonio/preservación y la relación entre los archivos y sus públicos.

PALABRAS CLAVE: Archivo; Patrimonio Audiovisual; Público(s); Festivales de Cine.

Recebido em: 26.01.2017. Aceito em: 26.03.2017. Publicado em: 01.04.2017. 


\section{Oevisto}

ISSN n² 2447-4266

Vol. 3, n. 2, Abril-Junho. 2017

DOI: http://dx.doi.org/10.20873/uft.2447-4266.2017v3n2p283

\section{Abertura}

Em 2015, na sede do Arquivo Nacional, no Rio de Janeiro, foi realizada a primeira edição do festival Arquivo em cartaz. O festival foi criado pelo Arquivo Nacional em 2015, após o encerramento do Recine, evento anual dedicado ao cinema de arquivo organizado pela instituição desde 2002. Em 2014, com o fim da parceria entre o Arquivo Nacional e a Rio de Cinema Produções por discordâncias no formato e funções do Recine, (MIRANDA, 2015, [n.p.]) o arquivo perdeu a marca registrada em nome da produtora; assim, surgiu o Arquivo em Cartaz. ${ }^{4}$

A iniciativa de criação do novo festival indica o intuito do Arquivo Nacional em consolidar seu lugar no debate sobre a preservação do patrimônio audiovisual no país, cuja importância é assinalada diversas vezes no catálogo da edição de abertura. O projeto se estabeleceu a partir de nova parceria agora selada com a Universo Produções. A produtora em questão é responsável pelo projeto Cinema Sem Fronteiras, dedicado à organização das mostras de cinema de Tiradentes e Ouro Preto, e do $\mathrm{CineBH}$, que vem se destacando no cenário dos festivais nacionais ao longo dos últimos anos.

Vale aqui mencionar que a parceria com a Universo Produções acabou por selar um elo entre este festival e o CineOP sob a coordenação da mesma produtora, no qual a preservação do patrimônio audiovisual também é um dos eixos centrais da programação e da concepção do evento ${ }^{5}$.

\footnotetext{
${ }^{4} \mathrm{O} 14^{\circ}$ Recine - Festival Internacional de Cinema de Arquivo foi realizado pela Rio de Cinema Produções em parceria com a Cinemateca do MAM, o Cine Arte UFF e o cinema Estação Botafogo, na cidade do Rio de Janeiro entre 14 e 23 de dezembro de 2015 . A $15^{\text {a }}$ edição do evento foi sediada nos mesmos espaços entre 27 de setembro e 5 de outubro de 2016.

${ }^{5}$ A Mostra de Cinema de Ouro Preto - CineOP promove o Encontro Nacional de Arquivos como parte de suas atividades, espaço no qual profissionais do setor se reúnem e debatem a formulação de políticas públicas. Como resultado desse trabalho que completará 12 anos em 2017, foram produzidas cartas anuais a partir do resultado dos debates, com destaque para a
} 


\section{Oevisto}

ISSN n² 2447-4266

Vol. 3, n. 2, Abril-Junho. 2017

DOI: http://dx.doi.org/10.20873/uft.2447-4266.2017v3n2p283

Conformaram-se, assim, ao longo dos últimos anos, festivais de cinema como espaços para a discussão e elaboração de políticas públicas, para o debate e criação de protocolos de guarda e conservação apropriados para a situação nacional e para a formação de públicos para o cinema nacional. A relação entre esses festivais proporciona condições para o estabelecimento e ampliação da rede de sujeitos envolvidos no debate e na promoção da preservação audiovisual em conjunto com a difusão.

A união entre essas duas funções dos arquivos fílmicos, conservar e difundir, tem sido um dos dilemas das cinematecas e acervos não apenas no Brasil. Os festivais são um dos momentos em que um arquivo se volta para o público, mas o modelo foi pouco adotado pelas filmotecas, tendo tido mais sucesso na Itália com dois eventos importantes, o Pordenone Silent Film Festival, promovido pela Cineteca del Friuli, criado em 1981, e /l Cinema Ritrovato, realizado pela Cineteca de Bolonha desde 1986 (QUARESIMA, 2009, p. 2).

O formato dos festivais é uma das soluções encontradas por arquivos fílmicos para tornar públicos seus acervos. De acordo com Quaresima (2009), essa escolha que se impôs na Itália trouxe consequências para as outras funções desses arquivos, como o acesso ao pesquisador, a conservação dos acervos e a própria divulgação, uma vez que uma programação constante foi substituída por um evento anual.

Essa questão envolvendo o acesso às obras das instituições de guarda do patrimônio audiovisual evoca uma querela que atravessa a história da FIAF International Federation of Film Archives, entre "os dirigentes que advogavam o

fundação da Associação Brasileira de Preservação Audiovisual em 2008, e a publicação do Plano Nacional de Preservação Audiovisual (2016). 


\section{Gevisto
Observatório}

ISSN n² 2447-4266

Vol. 3, n. 2, Abril-Junho. 2017

DOI: http://dx.doi.org/10.20873/uft.2447-4266.2017v3n2p283

primado da exibição sobre a preservação e vice-versa" (HEFFNER, 2002, [n.p]). De acordo com Heffner, trata-se de um falso problema, uma vez que as missões de guardar e tornar público são complementares, ainda que carregadas de forte tensão na história dos acervos cinematográficos.

A relação entre preservar e difundir tem sido enfrentada nas últimas décadas não apenas pelos arquivos fílmicos, mas pela arquivologia em geral, em meio a um processo de aproximação com outros campos como a história. Assim, nota-se a construção de um debate sobre a importância da relação entre a instituição dos arquivos (e também a história) e seus públicos.

Nesse sentido, busca-se compreender o surgimento de festivais de cinema promovidos por instituições arquivísticas como parte dessa preocupação com os públicos, costurando uma integração entre os diferentes circuitos sociais das imagens fílmicas - a produção, a distribuição, a circulação e a preservação da memória audiovisual.

A partir dessa discussão, busca-se localizar o surgimento do Recine e, posteriormente, do Arquivo em cartaz no interior da trajetória do Arquivo Nacional, debatendo o lugar dessa instituição no rol dos arquivos fílmicos nacionais. Por fim, pretende-se voltar ao tema dos acervos e seus públicos, a fim de traçar uma relação entre o que tem se proposto pela história pública e o trabalho realizado pelo Arquivo Nacional, a partir da organização dos dois festivais de cinema.

\section{Arquivos fílmicos}

Em Cine e historia, Michèle Lagny inclui uma reflexão sobre os espaços de guarda dos filmes, muitas vezes negligenciados pelos historiadores nas 


\section{Crevisto}

ISSN n² 2447-4266

Vol. 3, n. 2, Abril-Junho. 2017

DOI: http://dx.doi.org/10.20873/uft.2447-4266.2017v3n2p283

análises sobre as relações entre a historiografia e o cinema. Para Lagny (1992, p. 248), os arquivos fílmicos enquanto tais "são organismos dedicados à conservação e que também tem como função colocar os filmes a disposição dos investigadores, organizando projeções para dar a conhecer o patrimônio cinematográfico" ${ }^{\prime \prime}$.

Sob essa definição, a filmoteca está caracterizada a partir de uma dupla função entre conservar e exibir. Os arquivos são os espaços que permitem ao pesquisador interessado na memória audiovisual acessar não apenas os filmes, mas também uma série de documentos sobre a feitura e a circulação das obras, as políticas para o audiovisual, as salas de cinema, entre outros elementos. Há aqui uma relação entre cinefilia e o trabalho do pesquisador de cinema.

As cinematecas, ou filmotecas, surgiram na década de 1930/40, primeiramente na Europa e nos Estados Unidos, a primeira tendo sido fundada na Suécia em 1933, seguida pela Alemanha, Inglaterra, Estados Unidos e França. Em 1938, era criada a FIAF - Federação Internacional de Arquivos Fílmicos, que teria papel de destaque nas mudanças de mentalidade em torno da preservação cinematográfica, conformando um processo de "passagem da guarda exclusiva da película ao recolhimento conjunto dela e dos mais diferentes itens que gravitam em torno do filme como roteiros, boletins de continuidade e de marcação de luz, cartazes, fotos, documentos de produção, revistas de cinema" (HEFFNER, 2002, [n.p.]).

Desenhava-se, assim, nos anos 1940, o papel das cinematecas como

\footnotetext{
${ }^{6}$ Traduzido pela autora do original em espanhol: "Las filmotecas propriamente dichas son organismos dedicados a la conservación y que también tienen como función poner los filmes a disposición de los investigadores, organizando proyecciones para dar a conocer el patrimonio cinematográfico. Las más importantes se agrupan em um organismo internacional, la Fédération Internationale des Archives du Film (FIAF), que intenta, entre otras actividades, harmonizar las normas de conservación y las regras de clasificación y catalagación de los filmes."
} 


\section{Crevisto}

ISSN n² 2447-4266

Vol. 3, n. 2, Abril-Junho. 2017

DOI: http://dx.doi.org/10.20873/uft.2447-4266.2017v3n2p283

instituições, e o perfil do que se denominaria depois patrimônio audiovisual, partindo de uma definição do "cinema como documento e fato cultural em suas múltiplas manifestações" (HEFFNER, 2002, [n.p]). Desse modo, muito embora o tema da preservação já tivesse sido levantado muito antes, ainda no final do século $X I X^{7}$, uma preocupação sistemática com a salvaguarda dos filmes só se faria notar no pós-guerra, quando grande parte do que fora filmado nas primeiras décadas do cinema já havia se perdido.

A mudança a partir dos anos 1940 exigiu um projeto amplo que foi assumido, na maior parte dos casos, pelos Estados, dando origens a essas instituições de caráter nacional. Daí o lugar assumido pelas cinematecas surgidas nesse momento na esfera pública, voltadas para o debate amplo no contexto nacional sobre o patrimônio cinematográfico.

De acordo com Laura Bezerra (2015, p. 197), o processo de criação das cinematecas adquiriu contornos específicos no caso brasileiro, tendo ocorrido em meio ao crescimento de uma "cultura cinematográfica" no país. Desse modo, as filmotecas no país precederam o estabelecimento de uma discussão sobre a preservação do cinema nacional, preocupação que não estava no foco dos circuitos de cinefilia brasileiros antes dos anos 1940.

A falta de interesse pelo cinema brasileiro foi um obstáculo para o desenvolvimento de uma consciência voltada para a conservação. As duas primeiras filmotecas brasileiras, a Filmoteca do MAM-SP e a Cinemateca do MAM-RJ, ambas ligadas a museus de arte, surgiram não com essa preocupação de preservação, mas voltadas para a "difusão e reflexão sobre a sétima arte" (BEZERRA, 2015, p. 197).

\footnotetext{
${ }^{7}$ Ainda em 1898, Boleslaw Matuzewski publicou em Paris um texto intitulado Uma nova fonte histórica no qual defendia a criação de coleções cinematográficas. O texto foi traduzido para o português pela revista Contracampo em edição especial sobre a preservação, disponível em: <http://www.contracampo.com.br/34/frames.htm>. Acesso em: 14. jan. 2017.
} 


\section{Gevisto
Observatório}

ISSN n² 2447-4266

Vol. 3, n. 2, Abril-Junho. 2017

DOI: http://dx.doi.org/10.20873/uft.2447-4266.2017v3n2p283

Dessa forma, somente na década de 1970 surgiriam projetos para a preservação do acervo desses arquivos. A realização do / Simpósio sobre 0 Cinema e a Memória do Brasil em 1979, marcou uma mudança, colocando a memória audiovisual como problema das cinematecas do país. $O$ evento vinha fortalecer um movimento pela preservação por parte dos arquivos com acervos audiovisuais.

Nesse sentido, pode-se afirmar que a história dos arquivos fílmicos brasileiros constituiu de características próprias a tensão entre guardar/conservar e tornar acessível, grande desafio das filmotecas em geral. A partir dos anos 1970, notam-se, então, diversas tentativas de colocar a preservação num patamar de maior importância dentro dessas instituições, com investimentos consideráveis, ainda que insuficientes, em conservação, restauro e melhores condições de acondicionamento das matrizes.

Atualmente, os principais arquivos dedicados à memória audiovisual são a Cinemateca Brasileira, ligada ao Ministério da Cultura (MinC), a Cinemateca do Museu de Arte Moderna do Rio de Janeiro, o Centro Técnico Audiovisual - CTAv, também ligado ao MinC, e o Arquivo Nacional. As três primeiras instituições são filiadas à FIAF e participam, portanto, do principal fórum internacional de debate sobre o tema da conservação de materiais audiovisuais.

As duas primeiras instituições, as cinematecas de São Paulo e do Rio, foram criadas nos anos 1940, primeiramente voltadas para a exibição, seguindo o modelo do cineclube. Ligadas aos Museus de Arte Moderna de São Paulo e do Rio de Janeiro, respectivamente, desenvolveram tardiamente políticas específicas para a guarda adequada, conservação e restauro de seus acervos.

Em 2002, a Cinemateca do MAM-RJ, devido a problemas internos, declarou-se incapaz de preservar seu acervo e passou a transferir as matrizes 


\section{Gevisto
Observatório}

ISSN n² 2447-4266

Vol. 3, n. 2, Abril-Junho. 2017

DOI: http://dx.doi.org/10.20873/uft.2447-4266.2017v3n2p283

para outros órgãos. No ano seguinte, a decisão foi revogada e a mudança do acervo interrompida. Com esse gesto, considerável parte das matrizes e demais arquivos foram mantidos pela Cinemateca, que permanece como importante acervo para os pesquisadores de cinema. A instituição ainda conta com uma sala de exibição, muito embora a programação não seja constante.

No caso do Arquivo Nacional, a organização de uma seção específica para o acervo de imagens em movimento e de práticas de conservação voltadas para esse tipo de documento, datam apenas da década 1980, quando o Arquivo se tornou depositário dos acervos audiovisuais "de diferentes órgãos do governo federal, da extinta TV Tupi do Rio de Janeiro, do acervo do produtor de cinejornais César Nunes".

Já nos anos 2000, o Arquivo também se tornou local de guarda "do acervo da TV Educativa, e da Cinemateca do Museu de Arte Moderna", passando a ser o depositário de "parcela memorável da história do cinema brasileiro, como, por exemplo, os filmes da Atlântida Cinematográfica" (HOLLós, 2003: 103). A entrada do Arquivo Nacional no rol das instituições responsáveis pela guarda do patrimônio audiovisual nacional deu-se, assim, de forma tardia em relação aos arquivos fílmicos no país.

Desde os anos 1980, o setor de audiovisual do Arquivo Nacional sofreu grande ampliação, no início daquela década, o material audiovisual estava estimado em dois mil filmes, e, em 2003 o número chegava próximo a cem mil arquivos audiovisuais. Esse crescimento deve-se, em parte, à disposição do Arquivo, em receber o acervo da Cinemateca do MAM a partir de 2002. A transferência foi feita, mas apenas parcialmente, tendo sido interrompida em 2003, quando a Cinemateca voltou atrás da decisão de se desfazer dos arquivos. O episódio foi marcante, no entanto, para o crescimento do setor de 


\section{Crevisto}

ISSN n² 2447-4266

Vol. 3, n. 2, Abril-Junho. 2017

DOI: http://dx.doi.org/10.20873/uft.2447-4266.2017v3n2p283

audiovisual do Arquivo Nacional.

O ano de 2002 foi também o da criação do Recine - Festival Internacional de Cinema de Arquivo, organizado pelo Arquivo Nacional em conjunto com a Rio de Cinema Produções Culturais. Inicialmente Mostra Nacional de Filmes de Arquivo, o evento foi idealizado em torno do tema da preservação dos acervos audiovisuais. De acordo com o primeiro curador do evento, Clóvis Molinari Jr. (2003: 2), o Recine surgiu em meio a transformações do Arquivo Nacional, como a mudança de sede para o prédio atual (antiga Casa da Moeda) e a ampliação das políticas de acervo de imagens em movimento.

O Arquivo Nacional se destaca com uma trajetória distinta dos arquivos fílmicos do país nos quais a exibição e a reflexão voltados para os circuitos de cinefilia foram o motor das posteriores políticas de preservação audiovisual. No caso do Arquivo Nacional, a configuração como local de guarda e conservação de acervos audiovisuais precedeu a preocupação com a difusão dessas obras para o público.

\section{Arquivos em festival}

De acordo com Michèle Lagny, "as políticas de projeção das filmotecas, dos festivais ou de outras instituições culturais de vocação mais ampla,

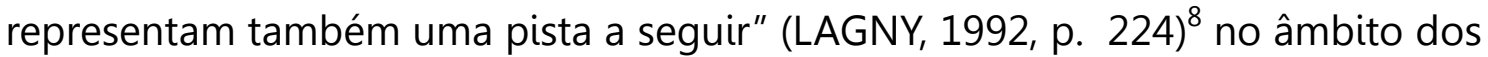
estudos sobre cinema e história. Essa pista aponta para diferentes circuitos, além das salas comerciais, por meio dos quais as obras cinematográficas

\footnotetext{
${ }^{8}$ Traduzido pela autora do original em espanhol: "Las políticas de proyección de las fimotecas, de los festivales o de otras instituciones culturales de vocación más amplia, representan también una pista a seguir, como por ejemplo, la aberta por la inserción del cine el los circuitos escolares y universitarios" (Lagny, 1992, p. 224)
} 


\section{Crevisto}

ISSN n² 2447-4266

Vol. 3, n. 2, Abril-Junho. 2017

DOI: http://dx.doi.org/10.20873/uft.2447-4266.2017v3n2p283

circulam e o cinema torna-se também objeto de reflexão da parte de pesquisadores e realizadores.

Nas últimas décadas os festivais de cinema tornaram-se espaços importantes de troca e distribuição de capital simbólico em um circuito mundial cada vez mais integrada e internacionalizado. Nota-se também o surgimento e crescimento de eventos especializados, como é o caso dos festivais de cinema de arquivo. Estes tem sido importantes para o reconhecimento do trabalho das filmotecas, tendo possibilitado um contato com obras dos primeiros anos da sétima arte que causaram forte impacto nos estudos historiográficos de cinema.

Desde 1979, quando, durante o Congresso da FIAF em Brighton, a exibição dos filmes da mostra Cinema 1900-1906 causou furor entre os pesquisadores presentes, a teoria e a história do cinema se tornaram mais próximas. Esse movimento levou importantes pesquisadores a um maior reconhecimento da importância da pesquisa histórica e da preservação para os estudos teóricos de cinema (GAUDREAULT, 2006).

Diante dos filmes restaurados, as bases dos estudos fílmicos e dos compêndios de cinema eram questionadas, a preservação e a exibição influenciavam as pesquisas. Nesse sentido, a relação entre festivais, arquivos de cinema e pesquisadores tem sido importante para definir novos rumos, conforme apontam Francesco Di Chiara e Valentina Re (2011) em texto sobre os impactos dos festivais na historiografia do cinema, com destaque para o festival /l Cinema Ritrovato, ligado à Cineteca de Bolonha, na Itália.

Evento criado na metade dos anos 1980, entre o surgimento de dois outros relevantes festivais sobre cinema e arquivo, Pordenone Silent Film Festival (1982) e Cinémémoire (1991), /l Cinema Ritrovato tem como característica a exibição de filmes recém restaurados sem restrição de um 


\section{Grevisto}

ISSN n² 2447-4266

Vol. 3, n. 2, Abril-Junho. 2017

DOI: http://dx.doi.org/10.20873/uft.2447-4266.2017v3n2p283

período na história do cinema. Transformou-se ao longo dos anos em espaço de debate das normas e desafios da preservação audiovisual, com destaque para o ano de 1994, quando o festival foi sede do $50^{\circ}$ Congresso Anual da $\mathrm{FIAF}^{9}$.

Desse modo, os festivais de cinema de arquivo denotam um empenho dos arquivos em enfrentar o tema do patrimônio, como preservá-lo para que seja acessivel para as próximas gerações e como torna-lo acessível, fazendo com que adquira sentido para a sociedade. Ainda de acordo com Di Chiara e Re (2011, p. 136), sobre o /l Cinema Ritrovato, "o festival claramente mostra a crescente preocupação dos arquivos fílmicos com as questões da preservação e promoção da herança cinematográfica".

Essa foi a grande motivação que orientou o surgimento do Recine, em 2002, no Arquivo Nacional. Centrado em torno da memória audiovisual brasileira e do papel dos arquivos responsáveis pela guarda desses acervos, o festival aparecia como um lugar de encontro entre a instituição de guarda (funcionários do Arquivo nacional e de outros arquivos), os distintos públicos e os profissionais do cinema.

Entre 2002 e 2014, as edições do festival aconteceram na sede do Arquivo Nacional no Rio de Janeiro, com programação gratuita e exibições ao ar livre no pátio do prédio. Consolidava-se, assim, um espaço para a troca e o debate sobre o patrimônio cinematográfico realizados na esfera pública, com proposta de ampliação do acesso ao espaço e aos documentos do arquivo.

Após o fim do Recine, ocasionado por diferenças entre o Arquivo e a produtora responsável pelo projeto, a criação do Arquivo em cartaz apontou

\footnotetext{
${ }^{9}$ A Cinemateca Brasileira foi sede do Congresso Anual da FIAF em 2006, na 62a edição do evento. Diferente do Arquivo Nacional, a Cinemateca optou por uma programação anual e pela colaboração com mostras e festivais, cedendo o espaço para as exibições e/ou debates.
} 


\section{Qrevisto}

ISSN n²447-4266

Vol. 3, n. 2, Abril-Junho. 2017

DOI: http://dx.doi.org/10.20873/uft.2447-4266.2017v3n2p283

mais uma vez para o lugar de relevância que o evento anterior assumiu na programação anual da instituição e no calendário de eventos do cinema nacional.

\section{Cinema de/no Arquivo: festivais, exibição e preservação do patrimônio audiovisual}

No Arquivo Nacional, a iniciativa de criação de um festival partiu da Coordenação de Documentos Audiovisuais e Cartográficos, com destaque para Clóvis Molinari Jr., que seria o primeiro curador do evento, posição que manteve até 2011. O ano era 2002 e o arquivo passava por transformações. Na edição de 2006, o catálogo do festival trazia a seguinte explicação que busca, retrospectivamente, resumir as condições e motivações do evento:

Quando o Recine nasceu, no ano de 2002, dispôs-se a reunir as mais atuantes instituições de acervos cinematográficos nacionais. Isso ocorreu no exato momento em que o Arquivo Nacional aumentava o seu acervo de filmes e completava a delicada restauração da sua nova sede - o magnífico conjunto arquitetônico da antiga Casa da Moeda. (RECINE, 2006, [n.p])

Colocar sob o mesmo espaço os principais profissionais e instituições de arquivo do país para debater o patrimônio audiovisual e sua sobrevivência, essa era a questão central do festival. Mas também exibir filmes antigos, trazer novos públicos para o Arquivo Nacional, que se instalava em nova sede com um amplo pátio, cenário privilegiado para as projeções.

A primeira edição foi organizada em formato de mostra de abrangência nacional, sem competição e voltada para as películas mais antigas de cinema mudo. No segundo ano, foi mantido o formato, modificando o tema para a 


\section{Grevisto}

ISSN n² 2447-4266

Vol. 3, n. 2, Abril-Junho. 2017

DOI: http://dx.doi.org/10.20873/uft.2447-4266.2017v3n2p283

censura cinematográfica. E não foi antes do terceiro ano de sua história que o evento ganhou formato mais amplo, tornando-se competitivo e incluindo novas atividades, como mostras informativas e oficinas. Então, o Recine se tornava Festival Internacional de Cinema de Arquivo.

No ano de 2004, foi criada uma revista que levou o nome do festival. Periódico anual, lançado a cada edição do festival, surgiu com o intuito de registrar e acompanhar o festival, trazendo artigos de pesquisadores, críticos e cineastas, além de entrevistas. A função de editor coube também a Clóvis Molinari Jr. e, posteriormente, por Renata Santos.

Já nesse primeiro número, a revista Recine trazia uma forte preocupação com as relações entre cinema e história, questão definidora do próprio festival. O tema das revoluções escolhido para a terceira edição daquele ano de 2004, enfatizou esse olhar do cinema para a história e vice-versa. Surgia um espaço importante para registrar reflexões sobre cinema de arquivo a cada ano, acompanhando o tema do festival.

Publicações semelhantes foram criadas em associação a festivais de cinema de arquivo ou desvinculadas de festivais, mas editadas por filmotecas. É o caso da revista Cinemathèque da Cinemateca de Paris, mas também de Cineteca e Cinegrafie (1989-2007) publicações anuais da Cineteca de Bolonha e ligadas ao festival /l Cinema Ritrovato, cujos números, segundo Di Chiara e Re (2011, p. 138), discutem questões sobre a exibição e a promoção dos acervos fílmicos.

Ainda no ano de 2004, teve início o trabalho das Oficinas de Vídeo. Essa atividade visava a promoção da cultura cinematográfica a formação de público, bem como situava o festival como entidade preocupada em fomentar o surgimento de novos filmes a partir de material de arquivo. Assim, desde a 


\section{Gevisto
Observatório}

ISSN n² 2447-4266

Vol. 3, n. 2, Abril-Junho. 2017

DOI: http://dx.doi.org/10.20873/uft.2447-4266.2017v3n2p283

terceira edição do evento, cineastas e pesquisadores de destaque do âmbito do cinema foram convidados, a cada ano, para orientar jovens profissionais da área do cinema ou nela interessados na confecção de curta-metragens produzidos a partir de acervos audiovisuais.

Os filmes resultantes desse processo eram exibidos em uma mostra específica no interior da competição, assim o festival tornava-se local de lançamento de novas obras. Nessa concepção as oficinas de vídeo tinham um papel de formação, que partia do princípio de que o trabalho de reutilização de imagens de arquivo como forma de estimular uma consciência a respeito da preservação audiovisual.

Esse trabalho educativo, ainda que voltado para um público específico, pode ser pensado dentro dos princípios de uma educação patrimonial, conceito que trabalha com a perspectiva de uma educação voltada para o "patrimônio cultural, apropriado socialmente como recurso para a compreensão sóciohistórica das referências culturais em todas as suas manifestações" (BEZERRA; CLEROT; RAMASSOTE; RAMPIM, 2014, p. 19).

Nesse sentido, estão inclú́dos como educação patrimonial tanto processos educativos formais como não formais, caso das atividades promovidas por museus e arquivos. As oficinas e demais atividades de caráter de formação e educação incluídas na programação do Recine dialogam com as diretrizes da educação patrimonial conforme desenvolvida pelo IPHAN, contribuem, assim, para a promoção de uma consciência cidadã sobre o patrimônio cultural, especialmente audiovisual.

A partir de 2012, as oficinas foram ampliadas e passaram a incluir também Oficinas técnicas voltadas para as atividades de conservação de documentos audiovisuais, sob orientação dos funcionários do arquivo. Nesse 


\section{Gevisto
Observatório}

ISSN n² 2447-4266

Vol. 3, n. 2, Abril-Junho. 2017

DOI: http://dx.doi.org/10.20873/uft.2447-4266.2017v3n2p283

caso, a instituição visa a expandir o conhecimento e experiência adquiridos para um público fora de seus muros, ainda que semi-especializado.

Também com esse objetivo de ampliar os públicos, havia a organização de sessões voltadas para os alunos de escolas da rede pública do Rio de Janeiro, em horários especiais, acompanhadas de debates.

A mostra competitiva, iniciada em 2004, seguia o critério de $40 \%$ de imagens de arquivo nas obras inscritas. A seleção do material era realizada por membros da organização do festival, do arquivo e da produtora. Posteriormente, um júri era formado para escolher dentre as obras selecionadas, as vencedoras de cada categoria de prêmios. Dentre as categorias existentes, estavam melhor curta-metragem, melhor longa-metragem, melhor filme da oficina, melhor uso das imagens de arquivo, inovação estética, além dos prêmios do júri popular.

A criação do Recine aconteceu em um momento de efervescência do setor de festivais no país. A temática da memória também não estava restrita ao espaço dos arquivos, estando a questão do acesso aos acervos relacionada a processos políticos mais amplos de construção e publicização de memórias na esfera civil e na academia, desde os anos 1980. Desde os anos 2000, um importante movimento pela abertura da documentação do período ditatorial foi encampado por instituição arquivísticas e acadêmicas do país, em um projeto de revelação de memórias e de abertura desses acervos ao público.

O tema da preservação audiovisual também ganhou novo fôlego nas últimas duas décadas, conforme aponta Laura Bezerra (2010). Nesse sentido, a criação de um festival específico para essa questão, por parte de um dos maiores órgãos dedicado à guarda de arquivos de imagens em movimento do país, não configurou atitude isolada ou menor, e deve ser analisada em relação 


\section{Grevisto}

ISSN n² 2447-4266

Vol. 3, n. 2, Abril-Junho. 2017

DOI: http://dx.doi.org/10.20873/uft.2447-4266.2017v3n2p283

com essa rede de projetos e discussões sobre a memória, o patrimônio e o direito de acesso e participação do público.

A divergência entre a produtora e o Arquivo na organização do Recine deu-se, como se observou anteriormente, a respeito dos papéis do festival. Enquanto os funcionários do arquivo desejavam manter o foco na questão dos acervos audiovisuais, perseguindo como objetivo a formação de público, a divulgação das técnicas de preservação, a reflexão e a exibição de obras voltadas para os usos da imagem de arquivo no cinema, a produtora procurava imprimir um formato mais comercial, deixando em segundo plano a problemática dos acervos.

Já no ano seguinte ao último Recine realizado pelo Arquivo Nacional, a instituição realizou a primeira edição do Arquivo em cartaz, que celebrava uma nova parceria agora com a Universo Produções. O novo evento mantinha o Arquivo no cenário dos festivais de cinema no país e, diferente do Recine, surgia a partir de um legado e experiência na organização conquistados ao longo de 13 anos.

A curadoria foi assumida por Antônio Laurindo, funcionário do Arquivo do Setor de Audiovisual que já havia participado da organização do Recine. No catálogo da edição de estréia, Laurindo explicou os fundamentos do Arquivo em cartaz, criado para promover um "espaço permanente de exibição, debate, formação e capacitação" (ARQUIVO EM CARTAZ, 2015, [n.p.]).

Junto com o festival foi lançada nova publicação do Arquivo, de mesmo título do evento, também voltada para os temas da memória e preservação audiovisual. A revista Arquivo em Cartaz acompanha as temáticas do festival e se soma a outras publicações de cinematecas e filmotecas, como a própria revista Recine que a antecedeu. Periódico anual, a nova publicação do Arquivo 


\section{Crevisto}

ISSN n² 2447-4266

Vol. 3, n. 2, Abril-Junho. 2017

DOI: http://dx.doi.org/10.20873/uft.2447-4266.2017v3n2p283

coloca em debate as várias dimensões da relação entre cinema e arquivo.

Voltado para a preservação e o acesso de imagens de arquivo e filmes realizados com arquivos audiovisuais, o Arquivo em Cartaz também inclui a preocupação com a capacitação e a formação de público expressa na sua programação de oficinas e atividades realizadas em parceria com escolas, estrutura que pode se dizer herança do festival anterior.

A mostra Arquivo faz Escola, que integra a programação do evento desde a primeira edição, inclui sessões específicas para escolas públicas do Rio de Janeiro, com o intuito de trazer o público escolar para o espaço do arquivo, convidando esses jovens e crianças a conhecer o cinema nacional. Nessa atividade, o cinema permite introduzir o debate sobre a preservação da memória audiovisual.

Em 2015 e 2016, as crianças e jovens também foram convidados a produzir vídeos, exibidos na Mostra Arquivos do Amanhã, atividade que tem por objetivo incentivar a produção de registros audiovisuais a partir do ponto de vista de estudantes, entre 8 e 17 anos, realizados no âmbito das atividades educacionais, que documentem fatos, lugares e tradições significativas de seu tempo e sirvam como memória para os arquivos do futuro.

Este projeto integra educação, preservação e produção audiovisual para um público que normalmente não é parte da audiência dos filmes nacionais. Nesse caso, uma atividade voltada para a promoção de uma consciência sobre a herança cinematográfica e sua importância é realizada através de um projeto de formação de público, com exibições e debates, mas principalmente por meio de uma proposta de ação que inclui o aluno como realizador, proporcionando um outro olhar para o tema dos acervos fílmicos.

Além dessas atividades, o Arquivo em cartaz também tem realizado 


\section{Gevisto
Observatório}

ISSN n² 2447-4266

Vol. 3, n. 2, Abril-Junho. 2017

DOI: http://dx.doi.org/10.20873/uft.2447-4266.2017v3n2p283

oficinas técnicas voltadas para a conservação de acervos audiovisuais, ministradas pela equipe do Arquivo Nacional. Esse trabalho está orientado para a capacitação de pessoal para manejo dessas documentações nos arquivos e para a promoção de um olhar especializado pra o pesquisador que lida com essa documentação.

A oficina de criação de filmes Lanterna Mágica segue princípios semelhantes às oficinas de realização de filmes do Recine. Nas duas primeiras edições do Arquivo em Cartaz, a oficina Lanterna Mágica foi coordenada pelo cineasta Joel Pizzini e reuniu inscritos interessados em realizar filmes de arquivo. As oficinas têm início meses antes do festival e consistem em aulas, atividades de orientação, além do acompanhamento das etapas de produção e edição das películas que são exibidas no festival, competindo entre si em uma mostra específica.

Outro aspecto importante do festival é o foco no papel dos arquivos audiovisuais, questão que mobilizou importante debate na primeira edição do evento, em 2015, na mesa Por Dentro dos Arquivos Cinematográficos, com a participação de representantes de diversas instituições arquivísticas responsáveis por acervos audiovisuais.

Por meio da análise do perfil dos festivais Recine e Arquivo em cartaz, pode-se afirmar que ambos tocam em um ponto nodal na história do cinema brasileiro, a preservação dos acervos que sempre esteve mais ou menos ameaçada pela falta de políticas institucionais. Dessa maneira, os festivais organizados pelo Arquivo Nacional colocam em debate, há mais de uma década, a relação entre cinema e memória, defendendo a importância de guardar e lidar com nossa herança audiovisual.

O tema da preservação também foi levantado em outros espaços, em 


\section{Gevisto
Observatório}

ISSN n² 2447-4266

Vol. 3, n. 2, Abril-Junho. 2017

DOI: http://dx.doi.org/10.20873/uft.2447-4266.2017v3n2p283

que se destaca a CineOP - Mostra de Cinema de Ouro Preto, na qual educação, preservação e história formam o eixo da programação do evento voltado para pensar o patrimônio. A mostra abriga o Encontro Nacional de Arquivos e o Fórum da Rede Kino sobre educação e audiovisual, tendo sido palco para a criação da Associação Brasileira pela Preservação Audiovisual no ano de 2012.

Esses eventos e entidades mostram o crescente interesse e preocupação da parte dos profissionais de arquivologia, cinema e história no importante tema da preservação audiovisual. Os esforços realizados apontam para a necessidade de se pensar de forma articulada as questões técnicas da conservação, os problemas históricos e teóricos da memória audiovisual e a educação patrimonial, unindo pesquisadores, cineastas, arquivistas e público.

\section{Conclusão: história, cinema, arquivos e públicos}

De acordo com texto de Paulo Emílio Salles Gomes (GOMES Apud BEZERRA, 2015, p. 197), publicado no Estado de S. Paulo em 1957, a existência de uma cinemateca seria uma condição necessária para a formação de uma cultura cinematográfica; esta, por sua vez, contribuiria para a consciência sobre a preservação. Desse modo, em um círculo virtuoso, o papel das filmotecas seria construir a ponte entre a conservação, a história e a memória audiovisual e o acesso, a difusão, a reflexão e os estudos de cinema.

Sabe-se que na história dos arquivos brasileiros essa relação não se deu de forma tão orgânica, tendo a difusão ocupado lugar de maior destaque durante quase toda a trajetória das instituições. Nas últimas décadas, contudo, esforços foram realizados para o fortalecimento da preservação, tendo os festivais de cinema de arquivo e de cinema e patrimônio sido parte desse 


\section{Gevisto
Observatório}

ISSN n² 2447-4266

Vol. 3, n. 2, Abril-Junho. 2017

DOI: http://dx.doi.org/10.20873/uft.2447-4266.2017v3n2p283

processo de disputa para a implementação de políticas públicas de preservação do patrimônio audiovisual.

A trajetória dos festivais de cinema no país carrega relação com o processo de criação das primeiras cinematecas e de valorização do cinema nacional, a partir dos anos 1950. Desde então, foram organizados seminários, simpósios e congressos de cinema brasileiro de caráter mais ou menos institucional e, a partir da década de 1960, surgiram os primeiros festivais de cinema, assim denominados.

O pioneiro foi o Festival de Brasilia do Cinema Brasileiro em 1965 - no interior do qual foi entregue o primeiro Prêmio Margarida de Prata da Confederação Nacional dos Bispos do Brasil (CNBB) -, depois o Festival de Gramado em 1973, a Jornada Internacional de Cinema da Bahia em 1972, seguidos da Mostra Internacional de Cinema de São Paulo em 1977 e do Rio Cine Festival em 1984 (Festival do Rio a partir de 1999).

Nos anos 1990 e 2000, houve um grande crescimento dos festivais, que passaram a se organizar como um setor do que se passou a denominar economia da cultura. Conforme observam Tetê Mattos e Antônio Leal no texto Festivais Audiovisuais Brasileiros: um diagnóstico do setor (2009), o período a partir dos anos 1990, é marcado pelo surgimento de diversos festivais voltados para temáticas e formatos específicos, como animação, documentário, cinema etnográfico, direitos humanos, cinema de arquivo, entre outros.

O surgimento do Recine, em 2002, ocorre em meio a um momento de crescimento dos festivais no país, com o surgimento de eventos temáticos. Aqui o cinema de arquivo, a preservação e os acervos cinematográficos e audiovisuais foram colocados como eixo de um festival organizado por uma instituição arquivística de destaque no país. Desse modo, a proposta levada a 


\section{Gevisto
Observatório}

ISSN n² 2447-4266

Vol. 3, n. 2, Abril-Junho. 2017

DOI: http://dx.doi.org/10.20873/uft.2447-4266.2017v3n2p283

cabo pelo Arquivo Nacional tinha características próprias que o singularizaram em meio ao conjunto de festivais.

Da mesma forma, o surgimento de uma relação entre festivais de cinema e a questão dos arquivos ocorrem, no Brasil, em meio a uma aproximação recente entre arquivologia e história. Desse contato têm sido elaboradas novas concepções sobre o papel dos arquivos em relação aos seus públicos, colocando-se a necessidade de expansão, diversidade e interação das pessoas com o espaço do arquivo/museu.

Um olhar diferenciado para o público também tem sido construído por parte da historiografia, especialmente a partir do crescimento da história oral desde os anos 1960. Dessa maneira, desde os anos 1970, observa-se, em vários países, o desenvolvimento de reflexões sobre o caráter público do trabalho do historiador, bem como sobre as diferentes formas de relação das sociedades com seus passados. Essas questões têm sido organizadas a partir da noção de história pública, que, no Brasil, já completa quase uma década de sistematização de trabalhos, pesquisas e encontros.

Um dos principais ramos dessas reflexões sobre a história e o espaço público tem sido a valorização de trabalhos desenvolvidos fora do ambiente acadêmico, por instituições como museus, arquivos, bibliotecas públicas e outros espaços de memória. Incluem-se nesse caso tanto a atuação de historiadores nesses espaços, como as pesquisas e atividades levadas a cabo pelas equipes desses locais voltadas para a memória, a história e o patrimônio, em relação com seus distintos públicos.

A noção de história pública abarca, assim, tanto a divulgação histórica, mas também atividades desenvolvidas por não historiadores, que desenvolvem outros tipos de relação com a história e o passado, de acordo com as suas 


\section{Oevisto}

ISSN n² 2447-4266

Vol. 3, n. 2, Abril-Junho. 2017

DOI: http://dx.doi.org/10.20873/uft.2447-4266.2017v3n2p283

necessidades e desejos (ALMEIDA, MAUAD, SANTHIAGO, 2016, p. 12).

As demandas atendidas pelos arquivos em sua relação com a história são distintas das preocupações dos historiadores acadêmicos, ainda assim, como observado por Di Chiara e Re (2011), existe uma relação recíproca entre o trabalho dos pesquisadores/historiadores e dos arquivos. Desse modo, existe um elo entre os estudos históricos/fílmicos e as atividades de conservação, preservação e restauro. O pesquisador também forma parte do público do arquivo, sendo uma audiência de tipo específico com suas próprias demandas.

Os arquivos lidam com públicos variados, para além dos pesquisadores, e têm buscado ampliar a abrangência e diversidade de suas ações a fim de atingir outras audiências. As instituições oferecem desde a possibilidade de conhecer os acervos e/ou até participar de atividades, visando a uma maior interação com as comunidades que os cercam. No caso do Arquivo Nacional, há grande circulação de pessoas em busca de informações sobre documentos e registros. Para além dos serviços de guarda, acesso e conservação dos acervos, o Arquivo promove exposições, eventos, cursos, debates, entre eles os festivais de cinema de arquivo.

O trabalho promovido nos últimos anos no âmbito do Recine, e mais recentemente do Arquivo em Cartaz, celebra, especialmente na forma das oficinas e nas atividades com as escolas, uma união entre fazer fílmico, produção e formação de público para o cinema nacional. Esses festivais promovem, assim, a relação entre cinema, história e público.

Nesse sentido, pode-se afirmar que os festivais de cinema de arquivo organizados sob a responsabilidade do Arquivo Nacional articularam exibição e preservação, na tentativa de superar uma dicotomia presente na história dos arquivos audiovisuais brasileiros. Esses festivais atuam na exibição e valorização 


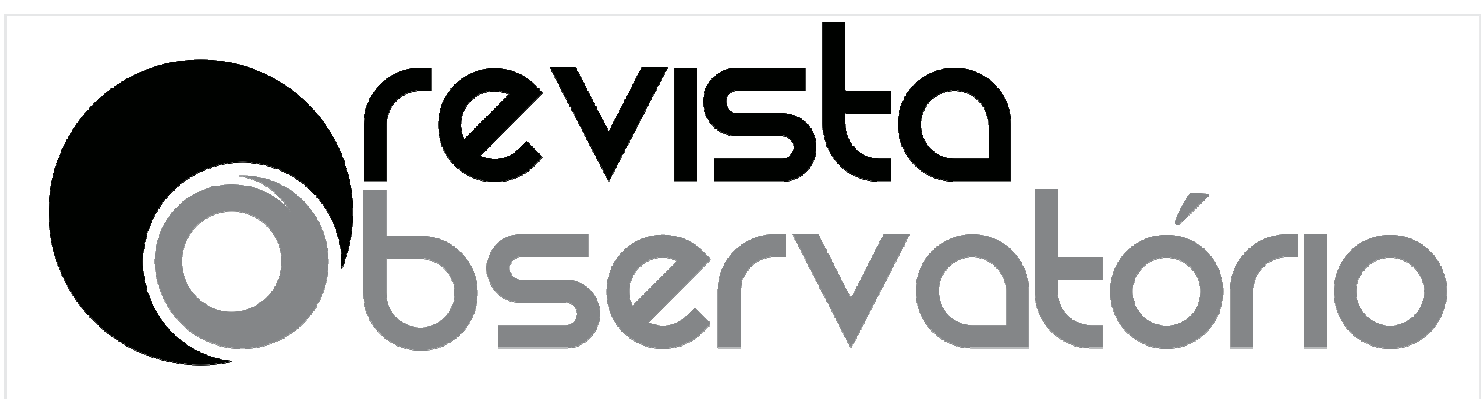

ISSN n² 2447-4266

Vol. 3, n. 2, Abril-Junho. 2017

DOI: http://dx.doi.org/10.20873/uft.2447-4266.2017v3n2p283

de acervos, contribuindo para a conservação das imagens de arquivo e da história e memória audiovisuais do país. Espera-se que ajudem a criar novas relações entre produzir, conservar, difundir e pesquisar cinema no Brasil.

\section{Referências}

\section{Catálogos}

RECINE. Festival internacional de cinema de arquivo (surrealismo, dadaísmo, futurismo, cinema experimental, construtivismo. Rio de Janeiro: Arquivo Nacional/Rio de Cinema Produções. 2006.

ARQUIVO em cartaz. Festival internacional de cinema de arquivo. Rio de Janeiro: Arquivo Nacional/Universo Produções. 2015.

\section{Livros, artigos e capítulos}

ALMEIDA, Juniele; MAUAD, Ana Maria; SANTHIAGO, Ricardo (Orgs.). Introdução. História Pública no Brasil: sentidos e itinerários. São Paulo: Letra e Voz, 2016. $354 \mathrm{p}$.

BEZERRA, Laura. Construindo um espaço para a preservação audiovisual no Brasil. Alceu, PUC-Rio, Rio de janeiro, n. 30, jan./jun., 2015. p. 195-210.

A preservação audiovisual no governo Lula. Anais do Seminário Internacional Políticas Culturais: teoria e práxis, Fundação Casa de Rui Barbosa, 2010. p. 1-16.

DI CHIARA, Francesco; RE, Valentina. Film Festival/Film History: The impact of film festivals on cinema historiography. Il Cinema Ritrovato and beyond. Cinèmas: Journal of Film Studies, Montreal, v. 21, n. 2-3, 2011. p. 131-151. 


\section{Crevisto}

ISSN n² 2447-4266

Vol. 3, n. 2, Abril-Junho. 2017

DOI: http://dx.doi.org/10.20873/uft.2447-4266.2017v3n2p283

GAUDREAULT, André. From "Primitive Cinema" to "Kine-Attractography". In: STRAUVEN, Wanda (Org.). The cinema of attractions reloaded. Amsterdam: Amsterdam University Press, 2006. p. 85-104.

HEFFNER, Hernani. Preservação. Contracampo, n. 34, 2002. Disponível em: <http://www.contracampo.com.br/34/frames.htm>. Acesso em: 20 jan. 2017

HOLLÓS, Adriana Cox. A preservação de filmes no Arquivo Nacional. Acervo, Arquivo nacional, Rio de Janeiro, v. 16, n. 1, jan./jun., 2003. p. 103-110.

BEZERA, Juliana; CLEROT, Pedro; RAMASSOTE, Rodrigo; RAMPIM, Sônia. Educação Patrimonial: histórico, conceitos e processos. Brasília, DF: IPHAN/Ceduc, 2012. 63p.

LACERDA, Aline Lopes de; MARQUES, Regina Celie Simões; SILVA, Jefferson Almeida. Arquivos históricos diante de novos públicos: um estudo exploratório. In: Anais do $2^{\circ}$ Simpósio Internacional de História Pública. Niterói: UFF, 2014. Disponível em: <http://historiapublica.com.br/wpcontent/uploads/2016/04/Anais-II-Simposio-RBHP-2014.pdf>. Acesso em: 18 jan. 2017.

LAGNY, Michèle. Cine e historia: problemas y métodos en la investigación cinematográfica. Barcelona: Bosch Casa Editorial, 1997. 306 p.

LEAL, Antônio; MATTOS, Tetê. Festivais audiovisuais brasileiros: um diagnóstico do setor. In: CALABRE, Lia (Org.). Políticas culturais: reflexões e ações. São Paulo: Itaú Cultural; Rio de Janeiro: Fundação Casa de Rui Barbosa, 2009. 305 p.

MATTOS, Tetê. Festivais pra quê? Um estudo crítico sobre festivais audiovisuais brasileiros. In: BAMBA, Mahomed (Org.). A recepção cinematográfica: teoria e estudos de casos. Salvador: EDUFBA, 2013. p. 117-131.

MIRANDA, André. Recine deixa a sede de sua criação, o Arquivo Nacional, após discórdia sobre marca. O Globo, Rio de Janeiro, 12 abril 2015. Cultura. 


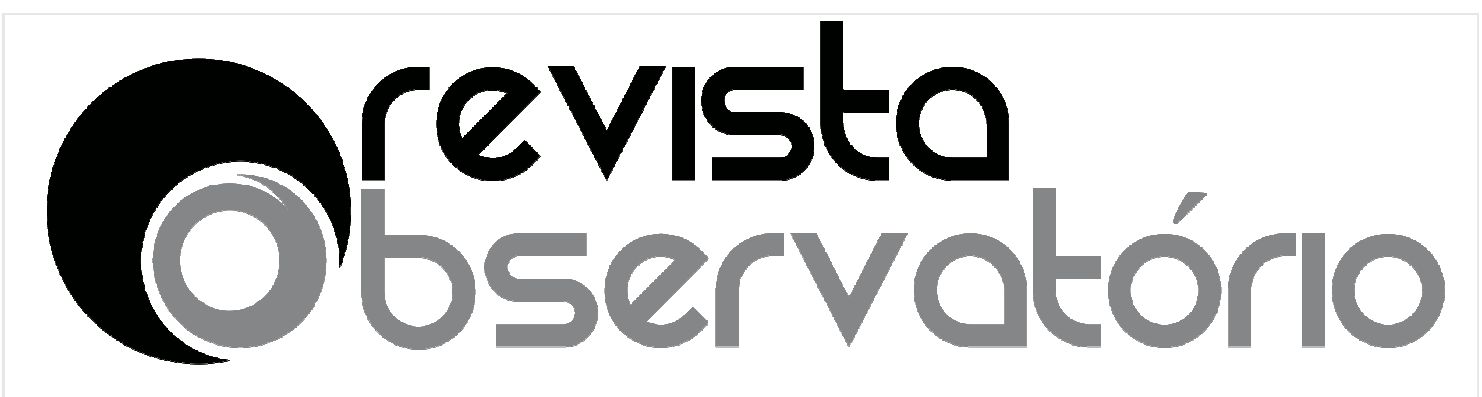

ISSN n² 2447-4266

Vol. 3, n. 2, Abril-Junho. 2017

DOI: http://dx.doi.org/10.20873/uft.2447-4266.2017v3n2p283

Disponível em: <http://oglobo.globo.com/cultura/filmes/recine-deixa-sede-desua-criacao-arquivo-nacional-apos-discordia-sobre-marca-15847719>. Acesso em: 14 jan. 2017.

MOLINARI JR., Clóvis. Apresentação (Dossiê Imagens em Movimento). Acervo, Arquivo Nacional, v. 16, n. 1, 2003. p. 1-8.

Apresentação. Recine - Revista do Festival Internacional de Cinema de Arquivo, Arquivo Nacional, v. 1. n.1, 2004. p. 7-9.

QUARESIMA, Leonardo. Recherche et archives en Italie: l'encrier de Schiller. Archimages: recherche/ archives, numériser les images, et aprés?, Institut National du Patrimoine, n. 9, 2009. Disponível em: <http://www.inp.fr/var/ezdemo_site/storage/original/application/9c62be7256bc 396bb5804d686d312621.pdf>. Acesso em: 18 jan. 2017. 